\title{
A 6 week quadruple drug regimen for the treatment of multibacillary leprosy
}

\author{
S. PATTYN \& S. GRILLONE* \\ Mycobacteriology Unit, Department of Microbiology, Institute of \\ Tropical Medicine, Antwerp, Belgium \\ *Service Lèpre-Tuberculose, Anjouan, République Fédérale Islamique \\ des Comores
}

Accepted for publication 23 October 1999

\section{Introduction}

Although the WHO recommended multidrug therapy regimen for multibacillary (MB) leprosy is highly effective, there is a need from the operational point of view ${ }^{1}$ to develop regimens of shorter duration.

We present here the results of a regimen of 6 weeks duration involving the supervised administration of four drugs, introduced in November 1989. Follow-up from 7 years on has become increasingly difficult as a result of political turmoil in the country. We therefore present the results as available.

\section{Patients and methods}

As in our previous studies, ${ }^{2-4}$ all patients were examined clinically, neurologically and bacteriologically; a copy of the clinical file was sent to Antwerp together with a skin biopsy fixed in $10 \%$ formalin. MB leprosy was defined as disease with a bacterial index (BI) of 2 or more at any of three sites from which slit-skin smears were prepared (one earlobe and two skin sites) and confirmed by histopathology.

Yearly follow-up examination identical to those at intake are performed. Patients received daily, 6 days a week, under supervision, rifampicin $600 \mathrm{mg}$, ofloxacin $400 \mathrm{mg}$, clofazimin $100 \mathrm{mg}$ and once a week minocycline $100 \mathrm{mg}$.

For follow-up, patients were invited to present to the National Leprosy Centre in the capital or to the regional Health Centres, where they were examined by the mobile teams and actively searched for as far as possible. This became more and more difficult from year 7 on.

Relapses were suspected clinically when new active looking lesions appeared. These were

Correspondence to: S. Pattyn 
confirmed by bacterial and histopathological examinations. All relapses had a BI of 4 or 5 with a proportion of solid staining bacilli after several negative BIs during the previous years.

The study was approved by the Ethical Committee of the Institute of Tropical Medicine, Antwerpen and the Ministry of Health of the Republic of the Comores.

\section{Results}

Between November 1989 and December 1993, a total of 136 patients giving their consent were taken into the study. At intake there were $18(13.2 \%)$ patients with a $\mathrm{BI}=2,21(15.4 \%)$ with a $\mathrm{BI}=3,73(53.6 \%)$ with a $\mathrm{BI}=4$ and $24(17.6 \%)$ with a $\mathrm{BI}=5$. All patients showed a rapid favourable clinical evolution. No major complications such as hepatitis or severe ENL requiring specific treatment were observed. No complaints of photophobia or skin discoloration were noted. As shown in Table 1, follow-up later than 6 years concerned considerably less than $50 \%$ of patients. The mean follow-up at year 6 was 4.7 years. During the first 6 years of follow-up, two relapses were diagnosed, at 56 and 60 months, respectively, after the start of treatment, giving rise to a cumulative relapse rate of $2 \%$. Six more relapses were diagnosed at $72,96,96,103,106$ and 111 months, respectively, after the start of therapy. Due to the small number of patients seen at 7-10 years of follow-up, calculations of cumulative relapse rates would be much misleading. At the start of therapy, the two patients relapsing at year 5 had a BI of 5. Among the six patients relapsing later, two had a BI of 4, the other had a BI of 5 .

Table 1. Number of patients taken in the study, their follow-up and appearance of relapses

\begin{tabular}{|c|c|c|c|c|c|}
\hline \multirow[b]{2}{*}{$\begin{array}{l}\text { Years of } \\
\text { follow-up }\end{array}$} & \multirow[b]{2}{*}{$\begin{array}{c}\text { Number of } \\
\text { patients }\end{array}$} & \multirow{2}{*}{$\begin{array}{c}\text { Cumulative } \\
\text { number of } \\
\text { patient years }\end{array}$} & \multicolumn{3}{|c|}{ Relapses } \\
\hline & & & Number & $\begin{array}{c}\text { Cumulative } \\
\text { number }\end{array}$ & $\%$ \\
\hline 1 & 136 & 136 & - & & \\
\hline 2 & 124 & 260 & - & & \\
\hline 3 & 121 & 381 & - & & \\
\hline 4 & 106 & 487 & - & & \\
\hline 5 & 88 & 575 & 2 & 2 & 2 \\
\hline 6 & 66 & 641 & - & 2 & 2 \\
\hline 7 & 52 & 693 & 1 & 3 & * \\
\hline 8 & 27 & 720 & 2 & 5 & $*$ \\
\hline 9 & 14 & 734 & 2 & 7 & * \\
\hline 10 & 3 & 737 & 1 & 8 & * \\
\hline \multicolumn{2}{|c|}{ Mean (up to year 6) } & 4.7 & & & \\
\hline
\end{tabular}

*Not calculated because low number of patients seen at the 7th year of follow-up. 


\section{Discussion}

The antileprosy drugs of the 1980s, ofloxacin and minocycline ${ }^{5-8}$ created new hopes for shorter treatment regimens in multibacillary leprosy. However, a treatment regimen consisting of the two drugs rifampicin and ofloxacin given daily for 4 weeks gave rise to an unacceptable high relapse rate of $2.9 \%$ or 11.5 per 100 patient years. ${ }^{9,10}$ In the present study, the quadruple regimen of daily rifampicin, ofloxacin, clofazimine and once weekly minocycline administered during 6 weeks, gave rise to a cumulative relapse rate of 2 per 100 patient years at year 6. Calculation of the relapse rate at years 7-10 when a continuously decreasing number of patients were seen would produce an unrealistic figure. In the absence of sufficient information concerning years 7-10 of follow-up, we cannot present a definitive result on the value of this regimen, only that it is superior to the 4 weeks daily rifampicin-ofloxacin evaluated at 5 years. It is noteworthy that in the present study, all relapsing patients had a BI of 4 or 5 at the start of treatment, as was the case in the study by Jamet et al. ${ }^{11}$ Minocycline being a bactericidal ${ }^{8,12}$ and long acting drug against Mycobacterium leprae ${ }^{12,13}$ and in order to avoid possible unexpected side effects of the drug combination, it was decided in 1989 to administer minocycline only once a week. It is possible that daily administration of minocycline would enhance the bactericidal action of this regimen. No skin or oral pigmentation was observed. Indeed, these complications appear only after years of minocycline intake. ${ }^{14,15}$

The strategy of multibacillary leprosy treatment has evolved along two main axes: either once monthly supervised treatment, completed by unsupervised drug intake, but for long duration, originally 24 months, now reduced to 12 months ${ }^{1}$ or daily drug intake of shorter duration. The Antwerp laboratory ${ }^{16}$ has been involved in studies of treatment regimens lasting 52, 34, 13 and 4 weeks duration, all involving only the drugs of the 1970s: rifampicin, ethionamide, dapsone or clofazimine. These studies showed that some regimens may be very promising during the first 5 years of follow-up but may give rise to cumulative relapse rates of 4 per 100 patient years at $8-9$ years of follow-up. ${ }^{16}$ The interpretation could be that 'early' relapses appearing during the first 5 years of follow-up are due to insufficient killing of originally actively multiplying organisms, while late relapses could be due to revival of dormant bacilli that resist all chemotherapeutic agents currently in use. Wayne ${ }^{17}$ and Wayne et al. ${ }^{18,19}$ showed that slow depletion of oxygen permits tubercle bacilli to adapt to a non-replicating state under microaerophilic conditions and enhance their ability to survive anaerobic conditions. This could account for long term latency of tuberculosis in the human host. Efforts to eradicate these bacteria should include agents killing these in both microaerophilic and anaerobic non-replicating stages. If this hypothesis of Wayne, sustained by experimental evidence, concerning $M$. tuberculosis is correct, and holds also for $M$. leprae, other fluoroquinolones active against anaerobes, such as clinafloxacin or trovafloxacin, should be studied in the treatment of leprosy in mice and in humans.

\section{Acknowledgements}

The Damien Foundation Brussels, Belgium supported the work in the field and in the laboratory. 


\section{References}

${ }^{1}$ Ji B. Why multidrug therapy for multibacillary leprosy can be shortened to 12 months. Lepr. Rev., 1998; 69: 106109.

2 Pattyn SR, Groenen G, Janssens L, Deverchin J, Ghys P. Combined regimens of one year duration in the treatment of multibacillary leprosy. I Combined regimens with rifampicin administered during one year. Lepr. Rev., 1989; 60: $109-117$.

Pattyn SR, Bourland J, Kazeze. Ambulatory treatment of multibacillary leprosy with a regimen of 8 months duration. Lepr. Rev., 1992; 63: 36-40.

4 Pattyn SR, Groenen G, Janssens L, Kuykens L, Mputu MB. Treatment of multibacillary leprosy with a regimen of 13 weeks duration. Lepr. Rev., 1992; 63: 41-46.

5 Pattyn SR. Activity of ofloxacin and pefloxacin against Mycobacterium leprae in mice. Antimicrob. Agents Chemother., 1987; 31: 671-672.

${ }^{6}$ Pattyn SR. Antimycobacterium leprae activity of several quinolones studied in the mouse. Int. J. Lepr., 1991; 59: 613-617.

7 Gelber RH. Activity of minocycline in Mycobacterium leprae-infected mice. J. Infect. Dis., 1987; 156: 236-239.

${ }^{8}$ Xiong J, Ji B, Perani EG, Petinon C, Grosset JH. Further study of the infectiveness of single doses of clarithromycin and minocycline against Mycobacterium leprae in mice. Int. J. Lepr., 1994; 62: $37-42$.

9 Ji B, Jamet P, Sow S, Perani EG, Traore I, Grosset JH. High relapse rate among lepromatous leprosy patients treated with rifampin plus ofloxacin daily for 4 weeks. Antimicrob. Agents Chemother., 1999; 41: $1953-1956$.

${ }^{10}$ Ganapati R, Pai VV, Revankar CR, Kingsley S, Buichand HO. Relapse of multibacillary leprosy after rifampin and ofloxacin treatment for 28 days; a case report. Int. J. Lepr., 1998; 66: 56-57.

11 Jamet P, Ji B and the Marchoux Chemotherapy Study Group. Relapse after long-term follow-up of multibacillary patients treated by WHO multidrug regimen. Int. J. Lepr., 1994; 63: 195-201.

12 Ji B, Jamet P, Perani EG, Bobin P, Grosset JH. Powerful bactericidal activities of clarithromycin and minocycline against Mycobacterium leprae in lepromatous leprosy. J. Infect. Dis., 1993; 169: 188-190.

13 Gelber RH, Siu P, Tsang M, Alley P, Murray LP. Effect of low level and intermittent minocycline therapy on the growth of Mycobacterium leprae in mice. Antimicrob. Agents Chemother., 1991; 35: 992-994.

14 Eisen D, Hakim MD. Minocycline-induced pigmentation. Incidence, prevention and management. Drug Saf., 1998; 18: 431-440.

15 Morrow GL, Abbott RL. Minocycline-induced scleral, dental, and dermal pigmentation. Am. J. Ophthalmol., 1998; 125: 396-397.

16 Pattyn SR. Search for effective short course regimens for the treatment of leprosy with a regimen of 8 months duration. Int. J. Lepr., 1992; 60: 234-243.

17 Wayne LG, Sramek HA. Metronidazole is bactericidal to dormant cells of Mycobacterium tuberculosis. Antimicrob. Agents Chemother., 1994; 38: 2054-2058.

18 Wayne LG. Dormancy of Mycobacterium tuberculosis and latency of disease. Eur. J. Clin. Microbiol. Infect. Dis., 1994; 13: 908-914.

19 Wayne LG, Hayes LG. An in vitro model for sequential study of shiftdown of Mycobacterium tuberculosis through two stages of non-replicating persistence. Infect. Immun., 1996; 64: 2062-2069. 